\title{
The general public's knowledge and perceptions about rheumatic diseases
}

\author{
Elly M Van Der Wardt, Erik Taal, Johannes J Rasker
}

\begin{abstract}
Objective-In the Netherlands, the mass media pay little attention to rheumatic diseases. For this reason, it might be assumed that in general people know very little about rheumatic diseases and thus have an unrealistic image of them. The purpose of this study was to gain insight into the general public's knowledge and perceptions regarding rheumatic diseases in the Netherlands.
\end{abstract}

Methods-A questionnaire was sent by mail to a random sample of 1800 Dutch homes; the response was 658. Questions mainly focused on knowledge, attitudes, behavioural intentions and use of the mass media with regard to rheumatic diseases. Results-The respondents gave the right answer to a mean of 8.2 statements out of 17 true/false statements regarding factual knowledge of rheumatic diseases. Respondents particularly underestimated the prevalence of rheumatic diseases and were unaware of several rheumatic disorders. Most respondents had rarely used the mass media to gain information about rheumatic diseases, but they did show a moderate interest in acquiring information. Knowledge correlated positively with the respondents' level of education, acquaintance with rheumatic patients, and use of the mass media. Knowledge correlated negatively with the idea that rheumatic patients are themselves able to influence the course of their disease. In general, respondents judged rheumatic diseases to be rather serious but did not feel very frightened or vulnerable of becoming a rheumatic patient. Fear of rheumatic diseases correlated positively with interest in information about rheumatic diseases, intentions of visiting a doctor if experiencing rheumatic complaints and helping rheumatic patients in daily life.

Conclusions-This study found that the public in general do not know very much about rheumatic diseases, but they do have a moderate desire for more information about them. Furthermore, they do not feel frightened of being confronted with a rheumatic disorder. More information about rheumatic diseases in the media might lead to better knowledge and perception of rheumatic diseases among the general public.

(Ann Rheum Dis 2000;59:32-38)
Some American studies have shown that the general public is not well informed about arthritis. ${ }^{12}$ These studies showed that the public is seriously misinformed as to the causes of arthritis and the nature and types of available treatments. Many respondents in these studies believed arthritis could be caused by poor diet, or cold and wet climates. In one study at least $50 \%$ believed in the effectiveness of treatments such as bee venom, vitamins, copper bracelets, or special diets, ${ }^{1}$ while in the other study most of these were rarely considered as effective treatments for arthritis. ${ }^{2}$ It was also found that the public mainly relies on the mass media for their information on arthritis. ${ }^{12}$ A study in the United Kingdom about two decades ago showed that the English public had fairly realistic ideas about arthritis. ${ }^{3}$ Only a minority believed that arthritis could be caused by cold weather or damp climates. However, they seemed to underestimate the impact of rheumatic disease in terms of disturbance of the normal pattern of daily life.

In the Netherlands, the mass media pay little attention to rheumatic diseases despite the prevailing high rates of rheumatic disorders. ${ }^{45}$ For this reason, it may be assumed that the general public knows little about rheumatic diseases; they may have an unrealistic image of these and misconceptions about causes, consequences and treatment modalities.

The purpose of this study is to gain insight into the general public's knowledge and perceptions regarding rheumatic diseases in the Netherlands.

\section{Methods}

SUBJECTS AND MEASURES

A postal survey was sent to a random sample of 1800 people, taken from a computerised database of the Dutch national telephone company (PTT) containing all Dutch private telephone subscribers by a simple random sampling procedure without any stratification. Almost every household in the Netherlands has a telephone subscription. The total number of households in the Netherlands is about 6500000 and the total number of subscribers within the national telephone company is about $8500000 .^{67}$ The required sample size for this study could not be calculated exactly. There was no primary variable on which to base sample calculations, but many variables and we wanted to study relations between several variables and differences between subgroups such as men and women. Furthermore, respondents who indicated to have a rheumatic disease would be excluded from the analyses, but it was not possible to calculate beforehand how large the
Accepted for publication 10 August 1999 
fraction of people with a rheumatic disease would be in our sample. Other postal surveys conducted at our department obtained response rates of about $40 \%,{ }^{89}$ but there is a declining trend of response rates in the Netherlands. ${ }^{10}$

Our sample size was therefore based on the following considerations:

For small differences between two groups (standardised effect size of 0.20 ) or a correlation of $r=0.20$ to be significant with $\mathrm{p}<0.01$ and a power of $80 \%$ at least 290 respondents are needed. We estimated that about $10 \%$ to $20 \%$ of the respondents would indicate to have a rheumatic disease. Therefore 320-360 respondents would be required. Based on a minimum response rate of $20 \%$ a sample of 1800 people was needed to get a minimum of 360 respondents and a net sample of at least 290 respondents.

The questionnaire consisted of questions on knowledge and beliefs about rheumatic diseases, fear of rheumatic diseases, behavioural intentions, use of the mass media for information, acquaintance with rheumatic patients and personal characteristics.

Knowledge about rheumatic diseases

("rheumatism")

Subjects were presented with 17 statements about rheumatic diseases (see table 2), and were asked to indicate for each statement whether they thought it was true or false, or that they did not know. Ten statements were true and seven were false. Statements were based on information provided about rheumatic diseases in educational brochures of the Dutch League against Rheumatism. The questions were put in simple understandable Dutch and the commonly used terminology was applied. Correctness of statements was verified by a rheumatologist (JJR). Internal consistency of the scale was good (Cronbach's $\alpha=0.77$ ).

Perceived seriousness of rheumatic diseases

Subjects rated the seriousness of 15 consequences of rheumatic diseases (see table 3 ) on a scale from 0 (not serious) to 3 (very serious). This scale had good internal consistency (Cronbach's $\alpha=0.89$ ). The list of 15 consequences was based on what arthritis patients themselves see as consequences of their disease ${ }^{11-13}$ and on what the mass media report as consequences of rheumatic diseases. $^{45}$

\section{Perceived susceptibility}

Perceived susceptibility for arthritis was measured with two five point rating scales with response options ranging from 1 (completely disagree) to 5 (completely agree):

(1) The chance that someone of my age and in my circumstances will develop a rheumatic disease is rather great.

(2) That I will develop a rheumatic disease is fairly likely.

These items were adapted from questions used in studies on the public's perceptions about cancer. ${ }^{814}$ The internal consistency of this scale was rather low (Cronbach's $\alpha=$ 0.52 ); however this scale consists of only two items.

Perceived behavioural influence

The idea that rheumatic patients can themselves influence onset and course of their disease was measured with three newly constructed items with response options ranging from 1 (completely disagree) to 5 (completely agree).

(1) I believe that one can do a lot to prevent oneself developing a rheumatic disease.

(2) Many people have themselves to blame if they develop a rheumatic disease.

(3) If one has a rheumatic disease, and follows the doctor's advice, then one will experience little trouble from the disease.

Internal consistency of the behavioural influence scale was good, if we take into account that the scale consisted of only three items (Cronbach's $\alpha=0.65$ ).

\section{Fear of rheumatic diseases}

Fear was measured with four items. Response options ranged from 1 (certainly not) to 5 (certainly).

(1) If I see a television programme about rheumatic patients in a wheel-chair I feel tense.

(2) I get anxious if I read an article about the side-effects of a medication that is frequently taken by rheumatic patients.

(3) I would get tense if I heard that a friend who was recently feeling unwell appeared to have a rheumatic disease.

(4) If I had pain in my neck and shoulders for some time, and I thought I had developed a rheumatic disease, I would become anxious.

This scale was an adaptation of a validated scale to assess fear of cancer. ${ }^{15}$ The scale has good internal consistency (Cronbach's $\alpha=$ $0.80)$.

\section{Behavioural intentions}

Six items asked about behavioural intentions regarding rheumatic disease. Response options ranged from 1 (certainly not) to 5 (certainly). These items were adapted from questions used in studies on the public's perceptions about cancer. $^{8}{ }^{14}$

Intentions to gather information about rheumatic diseases were measured with three items:

(1) If I received a leaflet from the Dutch League against Rheumatism in the mail, I would read it ...

(2) If there is a programme about rheumatic diseases on television, I'll watch it . . .

(3) If I see an article about rheumatic diseases in a newspaper or magazine, I'll read it ...

Cronbach's $\alpha$ was 0.83 , indicating good internal consistency.

Intentions to visit a doctor when experiencing rheumatic complaints were measured with two items:

(1) If I consistently felt pain and stiffness when rising, then I would go to my doctor. 
(2) I believe swelling in one or more joints to be suspect and this would cause me to visit my doctor for a complete check-up.

Internal consistency was good (Cronbach's $\alpha$ $=0.71$ ).

The intention to help a rheumatic patient was measured with one item:

(1) If I meet a rheumatic patient who has problems with shopping, I shall offer to help.

Use of the mass media for information on rheumatic diseases

Use of the mass media was measured with five items. Response options ranged from 0 (never) to 4 (very often). These items were adapted from questions used in studies on the public's perceptions about cancer. ${ }^{8} 14$

(1) Have you read a comprehensive article about rheumatic diseases in a newspaper or magazine in the last year?

(2) Have you watched a television programme about rheumatic diseases in the last year?

(3) Have you listened to a radio programme about rheumatic diseases in the last year?

(4) Have you ever read a leaflet from the Dutch League against Rheumatism?

(5) Have you ever read any other comprehensive information (such as medical literature, encyclopaedia, patient-magazine) about rheumatic diseases?

Internal consistency of this scale was good (Cronbach's $\alpha=0.80$ ).

\section{Personal characteristics}

Personal characteristics measured were age, sex, educational level, and medical education or education for a health profession, and acquaintance with rheumatic patients. Respondents are classified in three groups based on their educational level: Low: Elementary school and/or junior vocational training; Middle: junior high school or advanced vocational training; High: High school and senior vocational training or university.

Medical education or education for a health profession was assessed with one item:

Have you received training for a medical or health profession? (response options: yes/no).

Acquaintance with rheumatic patients was measured with one item. Response options ranged from 0 (none) to 4 (very many):

How many personal contacts with rheumatic patients did you have in the last 5 years?

\section{STATISTICS}

Differences in personal characteristics between the study sample and statistics of the Dutch population (obtained from the Statistical Yearbook ${ }^{16}$ ) were analysed with $\chi^{2}$ test. A total knowledge score was calculated by counting the number of knowledge statements that were judged correctly to be true or false. For all other scales of two or more items, mean total scores were calculated.

Relations between personal characteristics were examined with Pearson product-moment correlations, $t$ tests or $\chi^{2}$ tests. The level of significance for these analyses was set at $\mathrm{p}<0.05$.
Relations between knowledge, perceptions, fear, intentions and media use were analysed with Pearson product-moment correlations. Differences between men and women and between medically and non-medically educated respondents regarding knowledge, perceptions, fear, intentions and media use were analysed with analysis of covariance with other personal characteristics significantly related to sex or medical education as covariates. Relations of age, education level and acquaintance with rheumatic patients to knowledge, perceptions, fear, intentions and media use were analysed with partial correlations controlling for other significantly related personal characteristics. The level of significance for these analyses was set at $\mathrm{p}<0.01$.

\section{Results}

CHARACTERISTICS OF STUDY SAMPLE

Of the 1800 questionnaires sent out, 32 were returned unanswered because the addressee had died or had moved. Thus, the net sample of questionnaires sent out was 1768 . Ten weeks after sending out the questionnaires, 658 were returned, a response of $37.2 \%$. Because this study concerned a survey among the public, and not among patients, 89 questionnaires $(13.5 \%)$ from people who indicated having a rheumatic disease were excluded from the analyses. This left us with a final study sample of 569 people of the general public. A comparison of the characteristics of the study sample with the Dutch population over 20 years of age showed that our sample was representative in terms of sex, region of the country where one lives and work status (table 1 ). In the study sample younger people (20-39 years) and older people ( $\geqslant 65$ years), unmarried people and lower educated people were somewhat under represented, compared with the Dutch population.

Table 1 Characteristics of the study sample compared with the Dutch population * (data shown as percentages)

\begin{tabular}{|c|c|c|}
\hline & $\begin{array}{l}\text { Study sample } \\
(n=569)\end{array}$ & $\begin{array}{l}\text { Dutch population } \\
(n=15000000)\end{array}$ \\
\hline \multicolumn{3}{|l|}{ Sex } \\
\hline Male & 46.2 & 49.4 \\
\hline Female & 53.8 & 50.6 \\
\hline \multicolumn{3}{|l|}{ Age $(y) \dagger$} \\
\hline $20-39$ & 40.3 & 44.0 \\
\hline $40-64$ & 45.8 & 38.8 \\
\hline$\geqslant 65$ & 14.0 & 17.2 \\
\hline \multicolumn{3}{|l|}{ Marital status $\dagger$} \\
\hline Married & 68.0 & 61.9 \\
\hline Unmarried & 32.0 & 38.1 \\
\hline \multicolumn{3}{|c|}{ Region of home town } \\
\hline North & 9.5 & 10.6 \\
\hline East & 18.8 & 18.9 \\
\hline South & 24.3 & 24.5 \\
\hline West & 47.5 & 46.0 \\
\hline \multicolumn{3}{|l|}{ Education level $\ddagger$} \\
\hline Low & 29.9 & 34.7 \\
\hline Middle & 31.2 & 41.1 \\
\hline High & 38.9 & 24.2 \\
\hline \multicolumn{3}{|l|}{ Work status } \\
\hline Working & 53.9 & 57.5 \\
\hline Not working & 46.1 & 42.5 \\
\hline
\end{tabular}

* Statistics of the Dutch national population are obtained from the Statistical Yearbook of the Dutch Central Bureau of Statistics $^{6}$. $†$ Difference between study sample and the Dutch population statistically significant with $\mathrm{p}<0.01$. $\neq$ Difference between study sample and the Dutch population statistically significant with $\mathrm{p}<0.001$ 
Table 2 Knowledge about rheumatic diseases ('Rheumatism")

\begin{tabular}{|c|c|}
\hline & $\begin{array}{l}\% \text { correctly judged } \\
\text { true or false }\end{array}$ \\
\hline A rheumatic disease is especially characterised by pain and stiffness in muscles and joints $(t)$ & 89.5 \\
\hline Rheumatic diseases are only seen in older women (f) & 88.5 \\
\hline In general, rheumatic patients should rest as much as possible and move as little as possible ( $\mathrm{f}$ ) & 74.6 \\
\hline Almost all rheumatic patients will finally end up in a wheelchair (f) & 67.9 \\
\hline Medications for osteoarthritis cannot cure the disease, but can relieve pain and stiffness ( $t$ ) & 67.1 \\
\hline Glandular fever is a kind of rheumatic disease ( $\mathrm{f}$ ) & 63.7 \\
\hline Rheumatoid arthritis is a rheumatic disease in which the joints are affected with inflammations ( $t$ ) & 60.4 \\
\hline Affected joints of rheumatic patients can be replaced with artificial joints ( $t$ ) & 56.9 \\
\hline Osteoarthritis ("wear and tear") is the most common kind of rheumatic disease (t) & 46.1 \\
\hline Multiple sclerosis (MS) is a rheumatic disease (f) & 44.8 \\
\hline People can die from the consequences of rheumatic disease $(t)$ & 32.9 \\
\hline No kinds of rheumatic diseases can be cured (f) & 32.6 \\
\hline Rheumatoid arthritis is caused by poor diet, and cold and damp weather ( $f$ ) & 30.0 \\
\hline Ankylosing spondylitis is a kind of rheumatic disease $(\mathrm{t})$ & 23.5 \\
\hline There are more than 100 different kinds of rheumatic diseases $(t)$ & 22.6 \\
\hline About one out of every twenty Dutch people is being treated for a rheumatic disease $(t)$ & 17.1 \\
\hline Fibromyalgia is a rheumatic disease $(t)$ & 7.5 \\
\hline
\end{tabular}

(t), statement is true; (f), statement is false.

More women ( $\mathrm{n}=306 ; 53.8 \%)$ have participated in the study than men $(n=263 ; 46.2 \%)$. The mean age of the respondents was 46 years. Male respondents were significantly older ( 49 years) than female respondents (43 years; $t=$ $4.62, \mathrm{p}<0.001)$. Men had significantly higher education levels than women $(t=2.06, \mathrm{p}<0.05)$. Age was significantly negatively correlated $(r=-0.34, \quad \mathrm{p}<0.001)$ with education level, which means that younger respondents were relatively higher educated than older respondents.

Eighty five respondents (14.9\%) had been educated for a medical or health profession. Women were more often medically educated than men $\left(\chi^{2}=34.76, \mathrm{df}=1, \mathrm{p}<0.001\right)$. Medically educated respondents were significantly younger (39 years) than non-medically educated respondents ( 47 years, $t=4.29, \mathrm{p}<0.001$ ), and they were significantly higher educated $(t=3.20, \mathrm{p}<0.01)$.

The respondents had in general few contacts with rheumatic patients. The mean score was only 1.16 on a scale from 0 (none) to 4 (very much). Men had significantly fewer contacts with rheumatic patients than women $(t=2.27$, $\mathrm{p}<0.05)$; and medically educated respondents had significantly more contacts with rheumatic patients than those non-medically educated $(t=5.00, \mathrm{p}<0.001)$.

WHAT DO THE GENERAL PUBLIC KNOW ABOUT RHEUMATIC DISEASES?

The respondents gave the right answer to a mean of 8.2 statements out of 17 statements. Eight statements were correctly judged to be true or false by a majority of the respondents, while nine statements were judged correctly by less than $50 \%$ of the respondents (table 2 ).

PERCEIVED SERIOUSNESS, SUSCEPTIBILITY, AND BEHAVIOURAL INFLUENCE

"Pain" was judged as the most serious consequence of rheumatic diseases, followed by "deformities of the joints", "dependency on the help of others" and "physical restrictions in daily life" (table 3). "Side-effects of medications" was seen as the least serious consequence. In general the consequences of rheumatic diseases were judged as "rather serious" (table 4).
Table 3 Perceived seriousness of consequences of rheumatic diseases

\begin{tabular}{ll}
\hline & $\begin{array}{l}\text { Perceived } \\
\text { seriousness } \\
\text { Mean (SD) }\end{array}$ \\
\hline Pain & $2.41(0.67)$ \\
Deformities of the joints & $2.29(0.76)$ \\
Dependency on the help of others & $2.21(0.84)$ \\
Physical restrictions in daily life & $2.21(0.70)$ \\
Fear and uncertainty for the future & $2.13(0.78)$ \\
Fatigue and stiffness & $2.11(0.70)$ \\
Work or study restrictions & $2.09(0.76)$ \\
Relationship problems with spouse and family & $2.08(1.00)$ \\
Restricted activities, such as hobbies and sport & $1.97(0.79)$ \\
Increased financial costs & $1.95(0.87)$ \\
Feelings of loneliness and depression & $1.95(0.90)$ \\
Decreased social contacts & $1.91(0.94)$ \\
Incomprehension of social environment & $1.87(0.93)$ \\
The use of aids and appliances & $1.77(0.83)$ \\
Side effects of medications & $1.73(0.82)$ \\
\hline
\end{tabular}

The respondents did not believe to have a high risk of developing a rheumatic disease, and did not believe that rheumatic patients themselves can influence the onset and course of their disease (table 4)

FEAR OF RHEUMATIC DISEASES

The mean score for fear of 2.90 on a scale from 1 to 5 indicates that in general the respondents were not very frightened of rheumatic diseases (table 4).

BEHAVIOURAL INTENTIONS

The intention to gather information about rheumatic diseases was moderately positive (table 4). The respondents indicated that they would certainly visit a doctor if they would experience rheumatic complaints; they had high intentions of helping a rheumatic patient (table 4).

USE OF THE MASS MEDIA FOR INFORMATION ON RHEUMATIC DISEASES

The respondents had rarely consulted the mass media for information on rheumatic disease. The mean score was 1.05 on a scale from 0 (never) to 4 (very often).

RELATIONS BETWEEN KNOWLEDGE, PERCEPTIONS, FEAR, MEDIA USE AND INTENTIONS

Significant correlations between knowledge, perceptions, fear, media use and intentions are shown in table 4 . Knowledge was negatively 
Table 4 Mean (SD) scores and significant ( $p<0.01)$ Pearson product-moment correlations between knowledge, perceptions, fear, intentions and media use

\begin{tabular}{|c|c|c|c|c|c|c|c|c|c|c|c|}
\hline & Mean & Range & $(S D)$ & 1 & 2 & 3 & 4 & 5 & 6 & 7 & 8 \\
\hline 1 Knowledge & 8.22 & $0-17$ & $(3.44)$ & & & & & & & & \\
\hline 2 Seriousness & 2.04 & $0-3$ & $(0.51)$ & - & & & & & & & \\
\hline 3 Susceptibility & 2.90 & $1-5$ & $(0.99)$ & - & - & & & & & & \\
\hline 4 Behavioural influence & 2.11 & $1-5$ & $(0.83)$ & $0.18+$ & - & $0.13^{\star}$ & & & & & \\
\hline 5 Fear & 2.90 & $1-5$ & $(0.97)$ & - & $0.15 \dagger$ & - & - & & & & \\
\hline 6 Gathering information & 3.42 & $1-5$ & $(0.94)$ & $0.23 \dagger$ & - & $0.21 \dagger$ & - & $0.22 \dagger$ & & & \\
\hline 7 Visiting a doctor & 4.06 & $1-5$ & $(0.90)$ & - & $0.13^{\star}$ & - & - & $0.27 \dagger$ & $0.22 \dagger$ & & \\
\hline 8 Helping a patient & 4.20 & $1-5$ & $(0.85)$ & - & - & $0.19 \dagger$ & - & $0.26 \dagger$ & $0.27 \dagger$ & $0.23 \dagger$ & \\
\hline 9 Media use & 1.05 & $0-4$ & $(0.79)$ & $0.22 \dagger$ & - & $0.20 \dagger$ & - & $0.17 \dagger$ & $0.59 \dagger$ & $0.16 \dagger$ & $0.20 \dagger$ \\
\hline
\end{tabular}

${ }^{\star} \mathrm{p}<0.01 ; \dagger \mathrm{p}<0.001$ (two sided).

Table 5 Differences in knowledge, perceptions, fear, intentions and media use between men and women

\begin{tabular}{llll}
\hline & Range & $\begin{array}{l}\text { Men } \\
\text { mean score }\end{array}$ & $\begin{array}{l}\text { Women } \\
\text { mean score }\end{array}$ \\
\hline Knowledge & $0-17$ & 7.69 & 8.67 \\
Seriousness & $0-3$ & 1.96 & 2.12 \\
Susceptibility & $1-5$ & 2.86 & 2.95 \\
Behavioural influence & $1-5$ & 2.21 & 2.02 \\
Feart & $1-5$ & 2.75 & 3.03 \\
Gathering information $\dagger$ & $1-5$ & 3.14 & 3.66 \\
Visiting a doctor & $1-5$ & 3.94 & 4.16 \\
Helping a patient & $1-5$ & 4.08 & 4.31 \\
Media use† & $0-4$ & 0.89 & 1.20 \\
\hline
\end{tabular}

${ }^{\star} \mathrm{p}<0.01,+\mathrm{p}<0.001$; by analysis of covariance with medical education, age, education level and acquaintance with rheumatic patients as covariates.

Table 6 Partial correlations of age, education level, and acquaintance with rheumatic patients with knowledge, perceptions, fear, intentions and media use *

\begin{tabular}{llll}
\hline & Age & Education level & $\begin{array}{l}\text { Acquaintance with } \\
\text { rheumatic patients }\end{array}$ \\
\hline Knowledge & - & $0.16 \ddagger$ & $0.21 \ddagger$ \\
Seriousness & - & - & - \\
Susceptibility & $0.25 \ddagger$ & $-0.12 \dagger$ & $0.14 \dagger$ \\
Behavioural influence & $0.14 \dagger$ & - & - \\
Fear & - & $-0.20 \ddagger$ & - \\
Gathering information & $0.21 \ddagger$ & - & - \\
Visiting a doctor & $0.16 \ddagger$ & - & - \\
Helping a patient & $0.25 \ddagger$ & $-0.19 \ddagger$ & $0.30 \ddagger$ \\
Media use & $0.25 \ddagger$ & &
\end{tabular}

^Partial correlations with age are controlled for sex, medical education and education level; partial correlations with education level are controlled for sex, medical education and age; partial correlations with acquaintance with rheumatic patients are controlled for sex and medical education. $t \mathrm{p}<0.01 . \ddagger \mathrm{p}<0.001$ (two sided).

correlated with the idea that people themselves can influence the development and course of a rheumatic disease. This means that people who know much about rheumatic diseases do not believe that patients themselves can exert much influence on their disease. Knowledge was positively correlated with past consultation of the mass media for rheumatic diseases, and also with the intention to take in information in the future. This means that people with much knowledge about rheumatic diseases have consulted the mass media more often for information about these and are more interested in this information than people with less knowledge about rheumatic diseases.

THE ROLE OF PERSONAL FACTORS

Women perceived rheumatic diseases to be more serious, were more frightened of rheumatic diseases, were more intent on gathering information about rheumatic diseases, visiting a doctor if experiencing rheumatic complaints and helping a rheumatic patient, and had more often consulted the mass media for information on rheumatic diseases (table 5).

Medically educated respondents knew significantly ( $\mathrm{p}<0.001$ ) more (mean score= 11.06) about rheumatic diseases than non- medically educated (mean score $=7.74$ ), and medically educated people had significantly $(p<0.01)$ higher intentions of gathering information about rheumatic diseases (mean score $=3.78$ ) than those non-medically educated (3.35), as tested with analysis of covariance with sex, age, education level and acquaintance with rheumatic patients as covariates. There were no other significant differences between medically and non-medically educated respondents.

The age of the respondents was significantly positively correlated with their perceptions of susceptibility to arthritis, the idea that patients can influence the onset and course of their disease, their intentions to take in information about rheumatic diseases, to visit a doctor if experiencing rheumatic complaints and to help a rheumatic patient, and their use of the mass media for information on rheumatic diseases (table 6).

Education level correlated positively with knowledge about rheumatic diseases: higher educated respondents knew more about rheumatic diseases than less educated respondents (table 6). Furthermore, education level correlated negatively with perceived susceptibility, fear of rheumatic diseases, the intention to take in information about rheumatic diseases and the use of the mass media for information on rheumatic diseases. This means that higher educated respondents felt less susceptible to, and less afraid of, rheumatic diseases, and were less interested in information about rheumatic diseases than lower educated respondents.

The positive correlations between acquaintance with rheumatic patients and knowledge, perceived susceptibility, the intention to take in information and the use of the mass media for information on rheumatic diseases show that respondents with many personal contacts with rheumatic patients knew more about rheumatic diseases, felt more susceptible to them and were more interested in information about rheumatic disorders than respondents with fewer personal contacts with rheumatic patients (table 6).

\section{Discussion}

The response rate of $37.2 \%$ in our study is rather low, but is in line with the declining trend of response rates in the Netherlands over the past 15 years. ${ }^{10}$ Recent postal surveys in the Netherlands on the perceived risks of waste disposal technologies ${ }^{17}$ and in the United Kingdom on dietary intake ${ }^{18}$ obtained response rates of $23 \%$ and $45 \%$ respectively. There might be a potential bias in our study because 
there are less young and old people, unmarried people and people with low education in our sample compared with the Dutch population. But, although significant, these differences are small. Two American studies on the public's perceptions of arthritis were telephone surveys with $300^{1}$ and with 2533 respondents, ${ }^{2}$ and response rates of $64 \%$ and $68 \%$ respectively. In both studies $41 \%$ of the respondents had at least attended college which is comparable to the $38.9 \%$ of respondents with a high education level in our study. Price et al interviewed relatively more women (67\%) compared with our study (53.8\% female), but age levels were comparable. Dubbert et al did not provide details about the sex and age of their respondents. In an English study on the attitudes of the public to arthritis 503 persons were interviewed in their own homes. ${ }^{3}$ The number of women, and number of respondents in different age groups that were interviewed were highly comparable to our study (details on education level were not provided).

This study showed that in general, the public do not know much about rheumatic diseases (The respondents judged a mean of 8.2 statements correctly out of 17 true/false statements regarding factual knowledge of rheumatic diseases). They underestimated the prevalence of rheumatic diseases and were unaware of the various types. Many respondents incorrectly believed rheumatic diseases could be caused by poor diet and cold and damp weather. Similar results have been found in the two American studies, ${ }^{12}$ but a study in the United Kingdom showed that the public had fairly good knowledge about rheumatic diseases. ${ }^{3}$ We found that people with lower education and people who had few contacts with rheumatic patients knew less about rheumatic diseases.

The public judged rheumatic diseases to be rather serious but did not feel frightened or vulnerable, and did not believe that rheumatic patients can do much themselves to influence the course of their disease. The inaccurate belief that patients can influence the onset and course of a rheumatic disease is negatively correlated with knowledge. By improving their knowledge, people may become aware that patients are not responsible for the onset of their rheumatic disease and cannot influence the course of their disease. Pain, deformities of the joints, dependency on the help of others and physical restrictions in daily life were seen as the most serious consequences of rheumatic diseases by the respondents in this study. In studies in which rheumatoid arthritis or osteoarthritis patients were asked what they experienced as the main disadvantages of having a rheumatic disease, pain, dependency and physical restrictions were most often named, but deformities were seldom mentioned as a serious problem. ${ }^{11-13}$ 19-21 The general public had a fairly good idea about the most serious consequences of rheumatic diseases but overstated the importance of deformities.

The intentions of the public of visiting a doctor if experiencing rheumatic complaints and of helping a rheumatic patient were high. Knowledge correlated positively with interest in information but not with intentions to visit a doctor or to help a rheumatic patient. Beliefs about the seriousness of the consequences of rheumatic disease were not very strongly correlated with behavioural intentions. People who were more frightened by rheumatic diseases had higher intentions. People who felt more vulnerable about acquiring a rheumatic disease had more interest in information and greater intentions of helping a rheumatic patient but, surprisingly, susceptibility was not related to the intention to visit a doctor if experiencing rheumatic complaints.

Most respondents had not used the mass media often to get information on rheumatic diseases, but they did show a moderate desire for more information on rheumatic diseases. Media use was positively correlated with knowledge, susceptibility, fear and behavioural intentions.

More information about rheumatic disease in the mass media might lead to a better perception of rheumatic diseases in the general public. Special attention by the mass media could have the effect of placing rheumatic diseases on the agenda of those who lack direct experience of rheumatism. This would mean the beginning of the society's acceptance of rheumatic diseases, by which patients will be encouraged to emerge from anonymity. There exists a "market" for information on rheumatic diseases: the general public knows little about rheumatic diseases and indicates a desire for more information. Information in the media should be directed towards target groups. For instance younger people felt less susceptible to rheumatic diseases, had lower behavioural intentions and consulted the media less often for information than did older patients, and men perceived rheumatic diseases as less serious than did women, and were less frightened, had lower intentions and were less interested in information about rheumatic diseases. It is important for the media to report at the level of the lower educated people, because they seemed to have less knowledge about rheumatic diseases than higher educated people, felt more vulnerable about getting a rheumatic disease, but did not have higher intentions of visiting a doctor if experiencing rheumatic complaints.

Funding: this study was supported by grants from the Dutch Funding: this study was supported by grants from the Dutch Ministry of Health, Welfare and Sport (Ministerie van Volksgezondheid, Welzijn en Sport) of the Netherlands.

We wish to thank Ms W Burke for advice about the English.

1 Price JH, Hillman KS, Toral ME, Newell S. The public's perceptions and misperceptions of arthritis. Arthritis Rheum 1983;26:1023-8.

2 Dubbert ML, Sharp GC, Kay DR, Sylvester JL, Brownson RC. Implications of a statewide survey of arthritis in Missouri. Mo Med 1990;87:145-8.

3 Badley EM, Wood PHN. Attitudes of the public to arthritis. Ann Rheum Dis 1979; 38:97-100

4 Wardt EM van der. Reuma in Beeld [Rheumatic disease in focus]. PhD thesis [in Dutch]. Enschede: University of Twente, 1997

5 Wardt EM van der, Taal E, Rasker JJ, Wiegman O. Media coverage of chronic diseases. Semin Arthritis Rheum 1999; 28:333-41.

6 CBS, Centraal Bureau voor de Statistiek: http://www.cbs.nl/

6 CBS, Centraal Bureau voor de Statistiek: http://ww

8 Seydel ER. Kanker en het algemene publiek [Cancer and the general public]. PhD thesis [in Dutch]. Enschede: Univer-
(ind sity of Twente, 1989. 
9 Gutteling JM, Wiegman O. Gender-specific reactions to environmental hazards in the Netherlands. Sex Roles environmental haza

10 Vereniging voor beleidsonderzoek, Werkgroep dataverzameling. Zicht op non-respons?' [Perspective on nonresponse?]. Ubbergen: Uitgeverij Tandem Felixvol, 1996.

11 Cornelissen PGJ, Rasker JJ, Valkenburg HA. The arthritis sufferer and the community: a comparison of arthritis sufferers in rural and urban areas. Ann Rheum Dis $1988 ; 47: 150-6$

12 Taal E, Rasker JJ, Seydel ER, Wiegman O. Health status, adherence with health recommendations, self-efficacy and social support in patients with rheumatoid arthritis. Patient Education and Counseling 1993;20:63-76.

13 Van Lankveld W, Näring G, Van der Staak C, Van 't Pad Bosch P, Van de Putt L. Stress caused by rheumatoid arthritis: relation among subjective stressors of the disease, disease status, and well-being. J Behav Med 1993;16:309-22

14 Seydel ER, Taal E, Wiegman O. Risk-appraisal, outcome and self-efficacy expectancies: cognitive factors in preventive self-efficacy expectancies: cognitive factors in preventive
behaviour related to cancer. Psychol Health 1990;4:99-109.
15 Kuttschreuter M, Gutteling JM, Seydel ER, Wiegman O. Angst voor kanker [Fear of cancer]. Gezondheid and amenleving 1984;5:281-5.

16 CBS, Centraal Bureau voor de Statistiek. Statistisch faarboek 1993 [Statistical Yearbook 1993]. Den Haag: SDUUitgeverij/CBS-Publikaties, 1993.

17 Galetzka M. In the neigbourhood. Enschede: Twente University Press, 1998.

18 Steptoe A, Wardle J. Motivational factors as mediators of socioeconomic variations in dietary intake patterns. Psychol Health 1999;14:391-402.

19 Brown GMM, Dare CM, Smith PR, Meyers OL. Important problems identified by patients with chronic arthritis. S Afr Med J 1987;72:126-8.

20 Chamberlain MA, Buchanan JM, Hanks H. The arthritic in an urban environment. Ann Rheum Dis 1979;38:51-6.

21 Lorig KR, Cox T, Cuevas Y, Kraines RG, Britton MC. Converging and diverging beliefs about arthritis: Caucasian patients, Spanish speaking patients, and physicians. J Rheumatol 1984;11:76-9. 